\title{
CONTROLLED SWITCHING OF THE T402 TRANSFORMER IN THE KRIŽOVANY 400kV SUBSTATION
}

\author{
František Janíček* — Martin Mucha* \\ Karol Česnek ${ }^{* *}$ - Jozef Kováčik ${ }^{* *}$
}

\begin{abstract}
The paper deals with simulating the circumstances of switching surge and trigger current at switching-in of the T402 autotransformer recently installed in Križovany, with the tests conducted by means of ATP (Alternative Transient Program) simulation software for simulating transient electromagnetic phenomena. The target has been to determine temporal curves for the most critical surge instances against earth and between the phases and the curves for trigger current with and without surge limiters connected, and to determine by means of simulations the size and statistical frequency of switching surges and based on a controlled switching simulation, to describe the elimination of transient phenomena during the process and in reference to the simulations and to operating manual for the PSD02 Siemens control unit, suggest the required configuration settings for the unit.

K e ywords: switching surge, trigger current, substation, transformer, T402 transformer, EMTP - ATP, Križovany, surge current
\end{abstract}

\section{INTRODUCTION}

Issues relating to non-controlled switching of large transformers in very high voltage networks have been paid particular attention in available sources. Surge current in switching large transformers along with the respective switching surges are an additional strain upon very high voltage assemblies but also may result in network stability issues.

This paper deals with simulating switching surges in the newly installed T402 transformer in the Križovany substation conducted by means of ATP software for simulating transient electromagnetic phenomena. The results aim at determining statistical frequency of surge voltages when idle transformer switches in and determining temporal curves for the most critical surge voltages against earth and between phases and temporal curves for closing current with and without connected surge limiters. Moreover, curves are examined for switching off the transformer and a controlled switching automation example with the respective curves indicated that testify to eliminating transient phenomena in the process. In the last part in reference to the simulations conducted and to the Siemens PSD02 unit user manual, ideal setup parameters are suggested for the unit.

\section{MODEL DESCRIPTION}

Figure 1 shows the circuit layout of the model employed for simulating switching surges in switching on idle transformer. For examining the least favourable instances in terms of surge voltages, maximum voltages of $420 \mathrm{kV}$ and $242 \mathrm{kV}$ respectively have been set for the assemblies, with secondary and tertiary transformer windings idle. The TR402 and TR403 $400 \mathrm{kV}$ fields have been modelled by means of LCC component with view to layout and dimensions of respective bus bars and connections. With view to feedback effects of surge waves, the $400 \mathrm{kV}$ bus bar has not been connected to the network directly but through dedicated connections modelled as line elements with evenly distributed parameters. The line parameters have been defined in reference to measured values. The lines have been terminated with network connections modelled by means of ideal voltage source with surge impendance in a consecutive component assembly calculated in reference to 1-phase and 3phase shortcut surges to reach the Križovany substations while deducting line impendance values. The transformers have been modelled by means of BCT component as 3-phase autotransformers TR402 and TR403 with 5-core magnetic circuit and as three one-phase TR401 components. Based on label indications and measured current and output values at the source and for idle system, an alternative transformer scheme has been calculated. The transformer model also includes residual capacities of the different windings against earth and between each other. The model assembly further includes PTP residual capacities. Diverters are modelled by means of non-linear MOV_3 resistor component in which the defined VA characteristic of the $\mathrm{ZnO}$ limiter is modified for applicable $U_{T}$.

\footnotetext{
* Faculty of Electrical Engineering and Information Technology of the Slovak University of Technology in Bratislava, Ilkovičova 3 , 81219 Bratislava, frantisek.janicek@stuba.sk, martin.mucha@stuba.sk;

** VÚJE, a. s., Okružná 5, 91864 Trnava, cesnek@vuje.sk, kovacik@vuje.sk,
} 


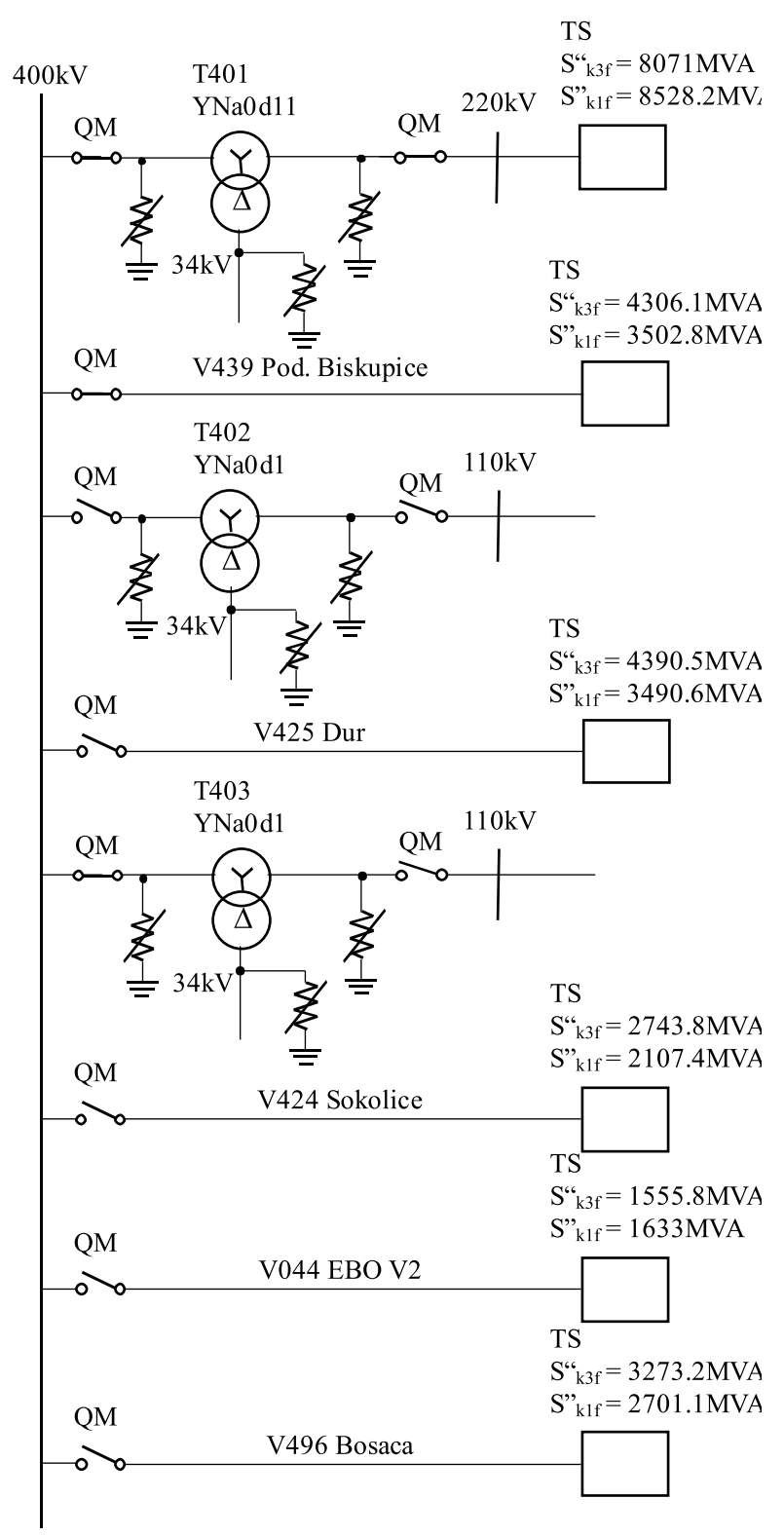

Fig. 1. Circuit layout for the mathematical model

\section{SWITCHING ON OF IDLE TRANSFORMER WITHOUT SURGE LIMITER}

The following Chapter provides the results for theoretical surge voltages in switching on idle transformer without attached surge limiter. In order to determine statistical frequency distribution for switching surges in switching on idle T402 transformer, simulations by means of ATP software have been conducted employing a special STATISTICAL SWITCH. Over the period of a network voltage cycle $(T=0.02 \mathrm{~s})$ for 20 evenly distributed points in the cycle in $\Delta t=1 \mathrm{~ms}$ intervals, 600 closing instances have been simulated for an identical mean closing time value; in total in each period for 20 selected points in the cycle, 12000 transformer switching on instances have been conducted with three switch contacts featuring Gaussian statistical distribution curve for each contact closing with a mean deviation of $\sigma=2 \mathrm{~ms}$. Based on the simulation results, percental frequency has been determined of surge voltage for each selected closing point in the cycle. By means of the approach, it has been ensured that the results comprise apart from the dependency of emergent surge voltage upon momentary voltage also surge voltage dependency upon the closing sequence of the different contacts while considering the closing delay between the different contacts. Along with the high number of closing instances, this ensures statistically relevant results that closely reflect real-life circumstances. In Table 1, average number is indicated for emergent surge voltages over the entire period and the dependency visualized in Figure 2. The significance of the different points is as follows: for instance the point that corresponds to the value of $k_{f}=1.9$ indicates that $20 \%$ of surge instances when switching on idle TR402 transformer was greater than or equal to 1.9 times the normal value. For better visualization, the surge values are quantified as phase-to-neutral surge coefficient defined as $k_{f}=\frac{u_{f p \max }}{\sqrt{2}(U / \sqrt{3})}$, where $u_{f p \max }$ is the peak value of phase-to-neutral surge and $U$ the effective value of stabilized phase-to-phase voltage for the network prior to the point of surge emergence.

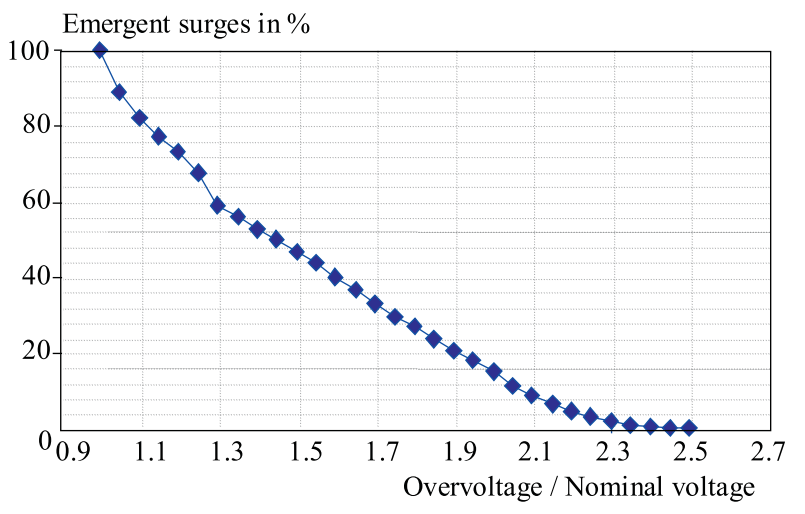

Fig. 2. Percental frequency distribution of emergent switching surges in non-controlled switching of idle TR402 Križovany without surge limiter connected over the entire period

In Fig. 2, the frequency curve is shown for emergent switching surges under non-controlled switching of idle TR402 over the entire period.

The peak phase-to-phase closing surge reached a value 2.5 times higher than nominal voltage $-815.9 \mathrm{kV}$ and $1150 \mathrm{kV}$ respectively between phases, ie, two times the value but less than nominal proof voltage for switching impulse against earth - $1050 \mathrm{kV}$ and $1500 \mathrm{kV}$ respectively between phases.

Temporal curves for maximum emergent surge voltages are shown in Figs. 3 and 4. Peak value for closing current in the initial period was $556.77 \mathrm{~A}$, switch recovery voltage was $538 \mathrm{kV}$ as shown in Figs. 5 and 6 . The closing current peak value caused by charging residual capacities did not occur this time as the most unfavourable circumstances in inductivity switching are the most favourable 


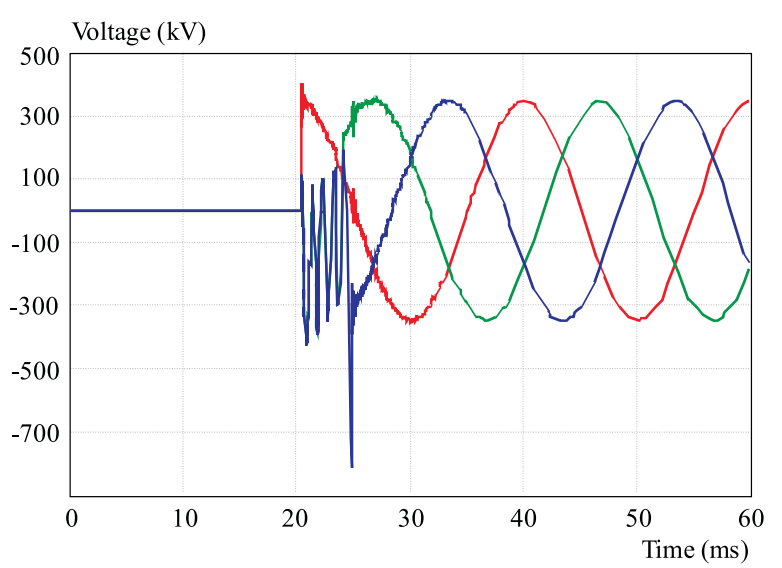

Fig. 3. Maximum phase-to-neutral surge voltage for primary connectors for TR402 Križovany for switching o idle TR402 without surge limiter

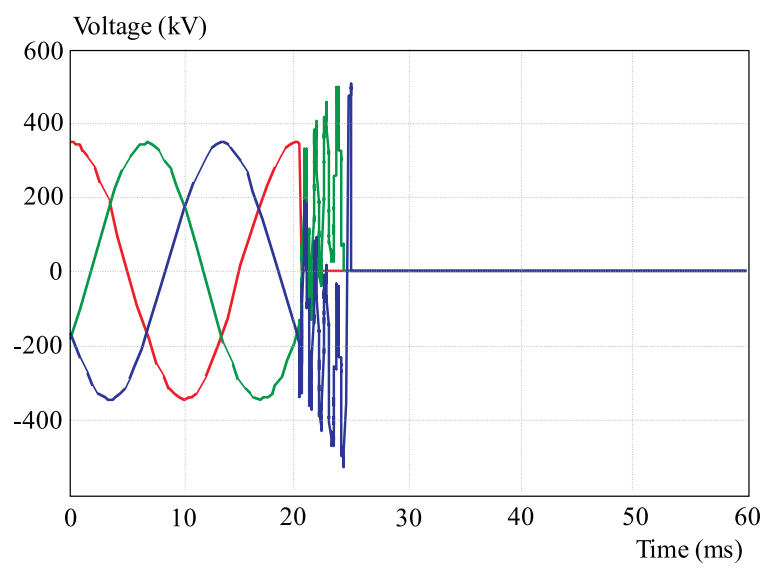

Fig. 5. Recovery voltage curve for the QM TR402 Križovany switch for switching on idle TR402 without surge limiter

in capacitor switching which is why the transient phenomenon practically did not occur in this instance. The high closing current in Fig. 6 at the point of transformer switching in is caused by the transformer connection to network at the most unfavourable point in the cycle when there is a zero voltage value and emergent offset magnetic current in the core that combines within the semiperiod with nominal magnetic current, hence the total magnetic current in core is twice the value of nominal magnetic current which is why the core material becomes saturated with magnetizing current reaching extreme values. The Fourier analysis results imply significant phenomena in the closing current initial period with significant one-way component and basic harmonic and significant $2^{\text {nd }}, 3^{\text {rd }}$ and $4^{\text {th }}$ harmonic. In the FFT area of the transient phenomenon becoming stabilized for the most unfavourable point in the cycle of transformer switching in, there is a comparable amount of higher harmonic as compared to basic harmonic due to transformer operating in the magnetizing curve saturation range for the transformer core material when idle but these are relatively small and comparable to current values for idle transformer.

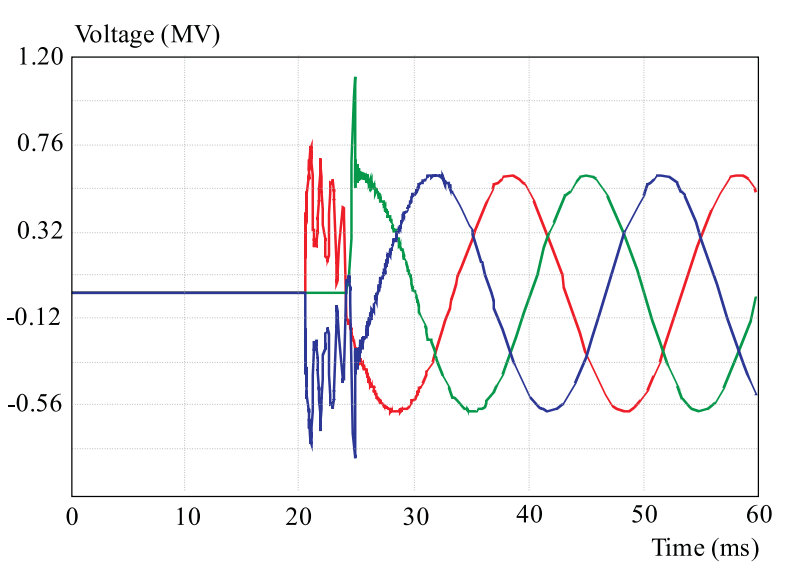

Fig. 4. Maximum interphase surge voltage for primary connectors for TR402 Križovany for switching on idle TR402 without surge limiter

Table 1. Mean Percentual Frequency Chart for Emergent Surge Voltages under Non-Controlled Switching of Idle TR402 Transformer over the Entire Period

\begin{tabular}{cccc}
\hline $\begin{array}{c}\text { Phase- } \\
\text { to-phase } \\
\text { surge } \\
\text { coeff. }\end{array}$ & $\begin{array}{c}\text { Emergent } \\
\text { surge } \\
\text { frequency } \\
(\%)\end{array}$ & $\begin{array}{c}\text { Phase- } \\
\text { to-phase } \\
\text { surge } \\
\text { coeff. }\end{array}$ & $\begin{array}{c}\text { Emergent } \\
\text { surge } \\
\text { frequency } \\
(\%)\end{array}$ \\
\hline 1 & 100 & 1.8 & 26.85 \\
1.1 & 81.95 & 1.85 & 23.65 \\
1.15 & 77.25 & 1.9 & 20.53 \\
1.2 & 72.9 & 1.95 & 17.88 \\
1.25 & 67.28 & 2 & 14.8 \\
1.3 & 59 & 2.05 & 11.3 \\
1.35 & 55.83 & 2.1 & 8.6 \\
1.4 & 52.65 & 2.15 & 6.5 \\
1.45 & 49.78 & 2.2 & 4.375 \\
1.5 & 46.68 & 2.25 & 3 \\
1.55 & 43.43 & 2.3 & 1.8 \\
1.6 & 39.975 & 2.35 & 0.9 \\
1.65 & 36.38 & 2.4 & 0.275 \\
1.7 & 32.98 & 2.45 & 0.1 \\
1.75 & 29.53 & 2.5 & 0 \\
\hline
\end{tabular}

Table 2. Average percental frequency of emergent switching surges in switching on idle TR402 over the entire period with 336/267 surge limiter

\begin{tabular}{cccc}
\hline $\begin{array}{c}\text { Phase- } \\
\text { to-phase } \\
\text { surge } \\
\text { coeff. }\end{array}$ & $\begin{array}{c}\text { Emergent } \\
\text { surge } \\
\text { frequency } \\
(\%)\end{array}$ & $\begin{array}{c}\text { Phase- } \\
\text { to-phase } \\
\text { surge } \\
\text { coeff. }\end{array}$ & $\begin{array}{c}\text { Emergent } \\
\text { surge } \\
\text { frequency } \\
(\%)\end{array}$ \\
\hline 1 & 100 & 1.4 & 53.18 \\
1.05 & 88.375 & 1.45 & 50.05 \\
1.1 & 82.38 & 1.5 & 47.08 \\
1.15 & 76.95 & 1.55 & 44.13 \\
1.2 & 71.93 & 1.6 & 39.88 \\
1.25 & 66.48 & 1.65 & 32.58 \\
1.3 & 58.65 & 1.7 & 17.88 \\
1.35 & 56.03 & 1.75 & 0 \\
\hline
\end{tabular}



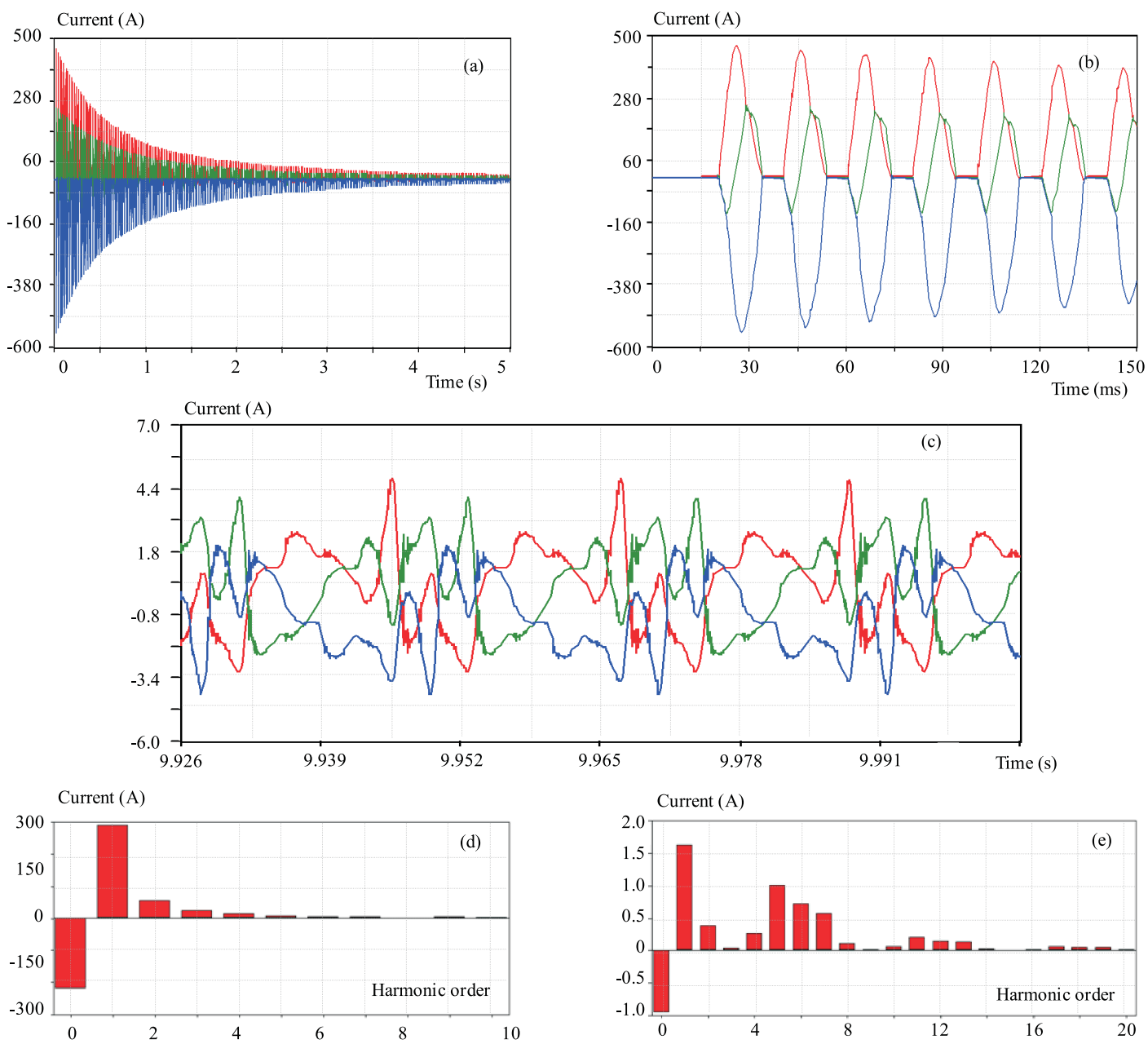

Fig. 6. Closing current curve for non-controlled switching of idle TR402 Križovany without surge limiter: (a) - overall curve, (b) detail for the initial phase, (c) - FFT for the initial period, (d) - detail after 10 seconds, (e) — FFT for the last period

Emergent surges in \%

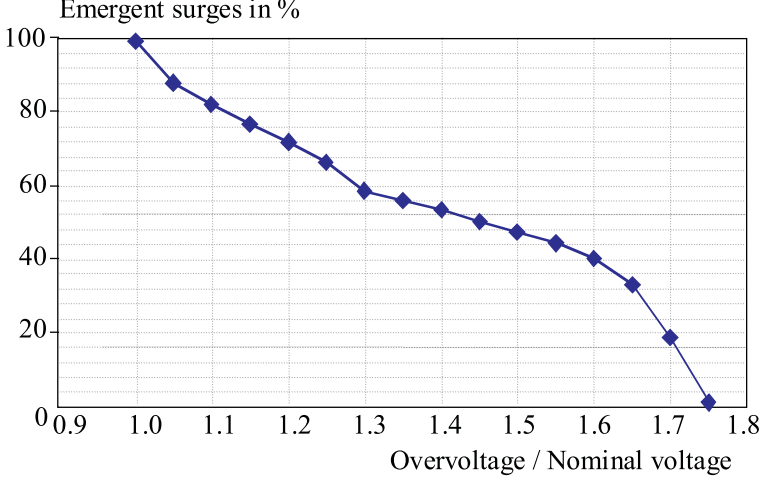

Fig. 7. Percental frequency curve for emergent surge voltages for non-controlled switching of idle TR402 Križovany over the entire period with 336/267 surge limiter

\section{SWITCHING ON OF IDLE TRANSFORMER WITH 336/267 SURGE LIMITER}

In this section, the results are listed for theoretical surge voltages in switching on idle transformer with connected surge limiter corresponding to real-life circumstances. All the reference assumptions apply as described in the initial section. Surge voltages were limited to 1.75 times the nominal value of phase-to-neutral voltage.

Peak phase-to-neutral switching surge reached 1.75 times the nominal value $-599.5 \mathrm{kV}$ and $872 \mathrm{kV}$ respectively between phases, ie 1.54 times, yet this is less than nominal proof voltage for switching impulse against earth - $1050 \mathrm{kV}$ and $1500 \mathrm{kV}$ respectively between phases.

Temporal curves for peak emergent surge voltages are shown in Fig. 8 and 9. Peak value for closing current reached $556.75 \mathrm{~A}$ in the initial period, the switch recovery voltage was $538 \mathrm{kV}$ as shown in Figs. 10 and 11.

\section{CONTROLLED SWITCHING ON OF IDLE TRANSFORMER WITHOUT SURGE LIMITER}

In order to prevent transient phenomena and the related switching surges in controlled inductivity switching, voltage needs to be applied through switch at the peak point as inductivity current is delayed by one fourth of the period, hence equals zero at the point. For threephase transformers with earthed neutral, this would mean to connect the different phases in a sequence of their maximum voltage, $i e$, each delayed compared to previous 


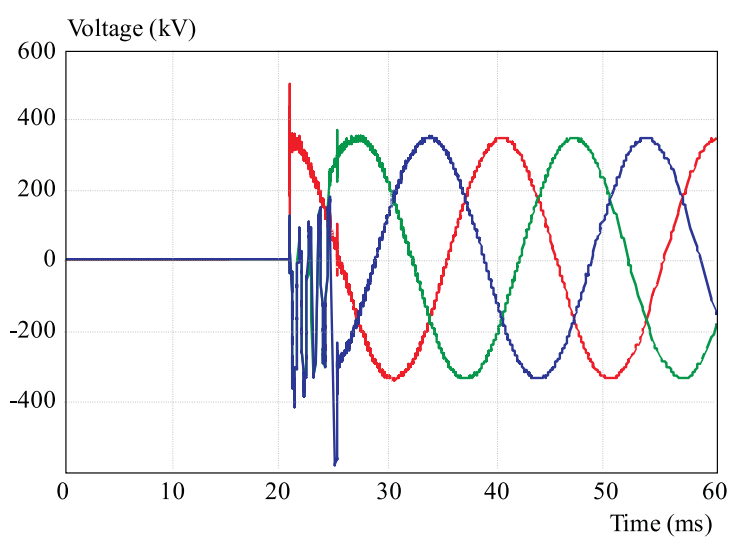

Fig. 8. Peak phase-to-neutral surge voltage curve for primary connectors of TR 402 Križovany for switching on idle TR402 Križovany with connected 336/367 surge limiter

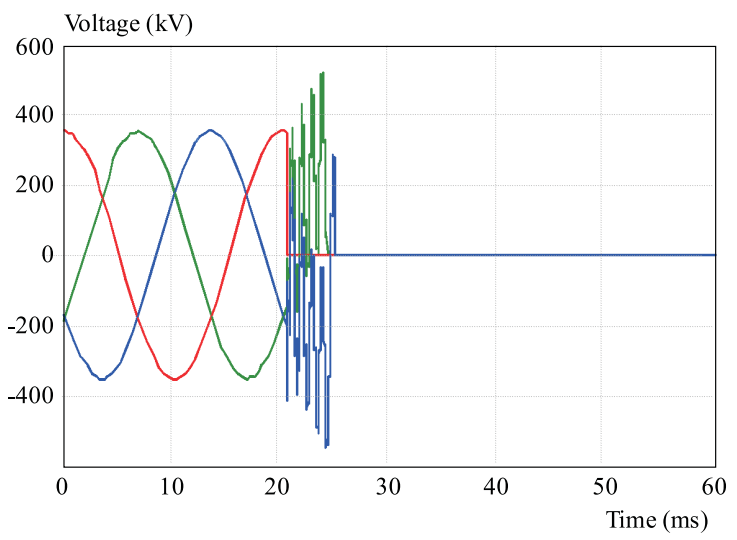

Fig. 10. Recovery voltage curve for the QM TR402 Križovany switch in switching on idle TR402 with connected 336/367 surge limiter

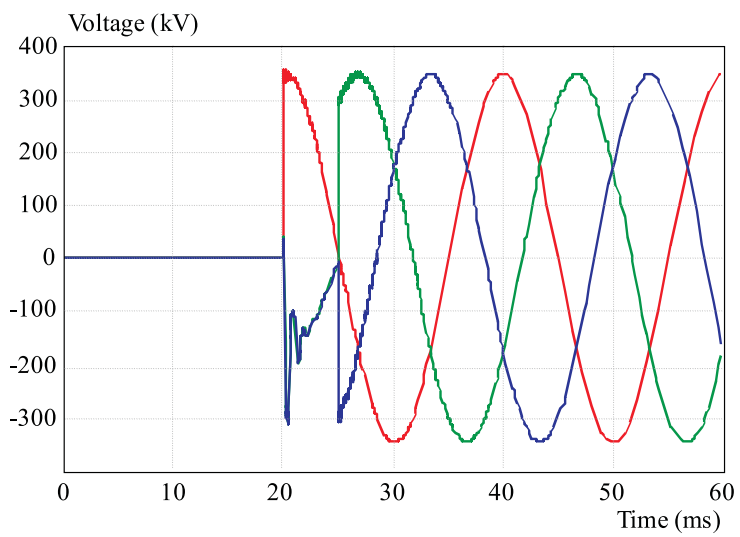

Fig. 12. Phase-to-neutral voltage curve for primary connectors of TR402 Križovany in controlled switching

phase by one third of the period. However, due to magnetic coupling between the different phases, the closing sequence would not prevent switching surge from emerging. For switching idle three-phase transformers with earthed neutral, one phase is applied at the peak of its supply voltage (with acceptable tolerance of $2 \mathrm{~ms}$ from the peak credit to fair gradient of the sine curve in the area). For sudden changes, voltage affects inductivity immediately, $i e$, one phase remains at nominal voltage and magnetic current in the respective part of the transformer core also

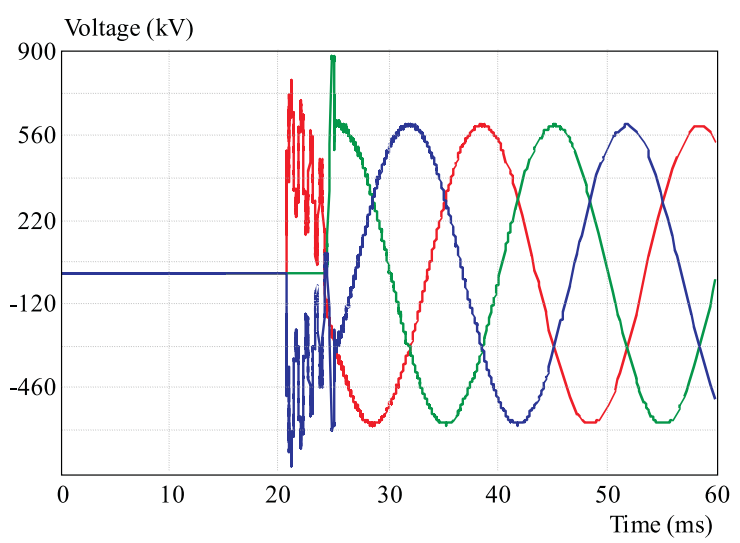

Fig. 9. Peak interphase surge voltage curve for primary connectors of TR402 Križovany for switching on idle TR402 with connected $336 / 367$ surge limiter

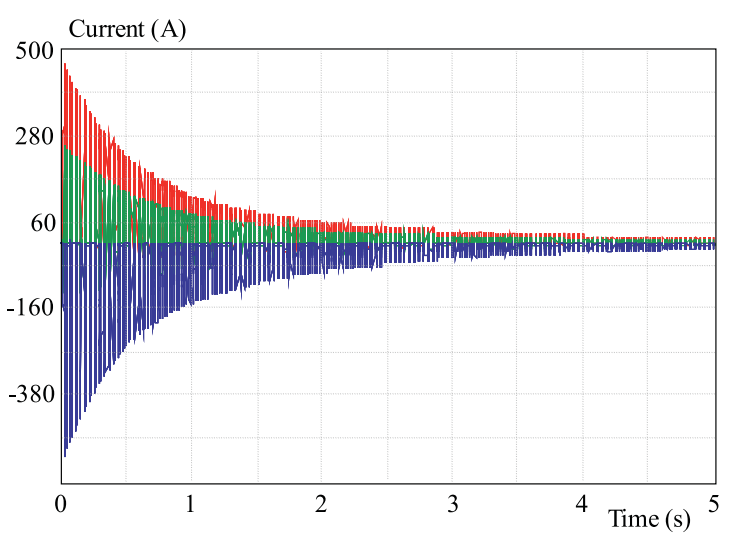

Fig. 11. Closing current curve for non-controlled switching on of idle transformer TR402 Križovany with connected 336/367 surge limiter

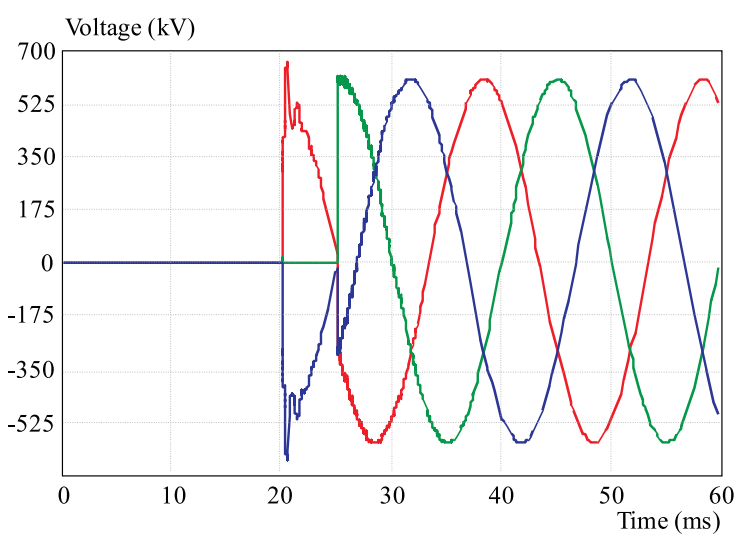

Fig. 13. Phase-to-phase voltage curve for primary connectors of TR402 Križovany in controlled switching

increases to nominal value. The current is separated by the remaining part of the core in which magnetic current is not generated by the remaining windings. If the remaining two phases are applied simultaneously one fourth of a period of $5 \mathrm{~ms}$ (peak point of phase-to-phase voltage between the two phases) after the first phase as their values are equal in nominal terms yet of opposite polarity (magnetic current generated by the first winding voltage being zero at the point, zero voltage exposure time), magnetic current for the remaining two windings remain separated 

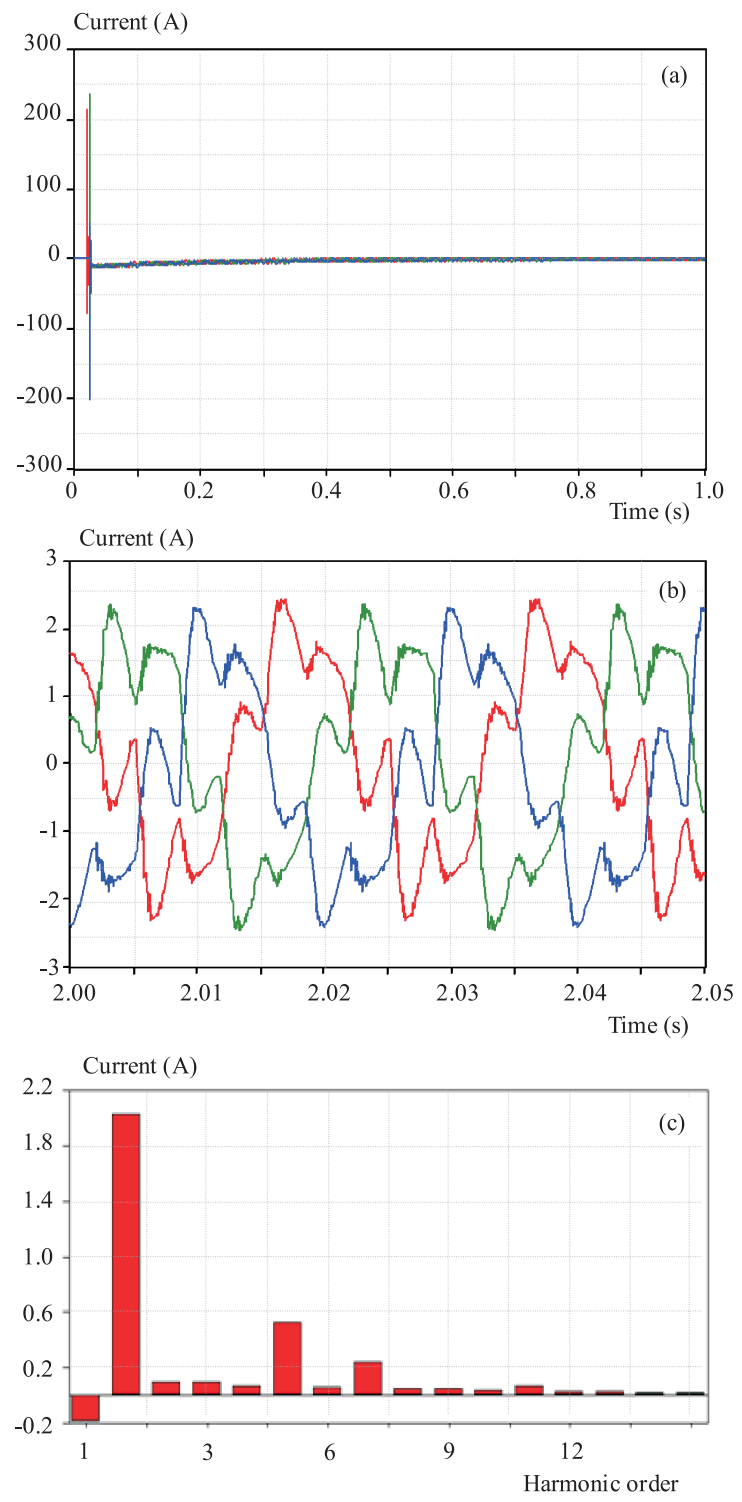

Fig. 14. Closing current curve for three phases for TR 402 Križovany: (a) - in controlled switching, (b) - detail, (c) - FFT analysis

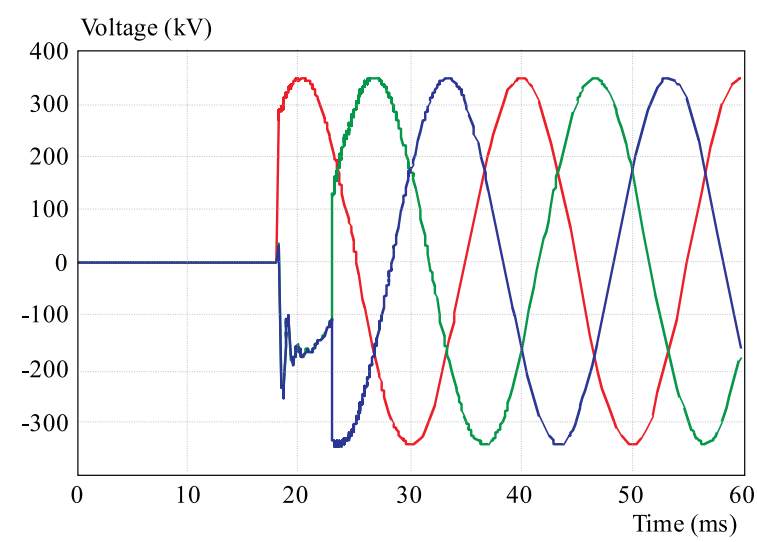

Fig. 15. Phase-to-neutral voltage curve for primary connectors of TR402 Križovany in controlled switching with early phase switching by $2 \mathrm{~ms}$ against peak values

in their respective parts of core and negate each other (under the scenario, there is no sudden change in magnetic current), there are no transient phenomena and hence no surge voltages occur. In setting up switching time in practical applications, the mechanical closing time needs to be considered for each pole in the switch and arc preignition time in the switch at maximum phase-to-neutral voltage for the first phase and at half the value of peak phase-to-phase voltage for the remaining three phases. The curves for phase-to-neutral and phase-to-phase voltages for primary connectors of T402 Križovany and the curve for closing current in controlled switching are shown in Figs. 12, 13 and 14. In controlled switching, closing current equals idle transformer current. The peak value for 240 A closing current is the charging current of residual capacities; in a model that does not include the capacities, there would be no peak value in closing current for the transformer. In controlled switching, the transient phenomenon is the most pronounced. In this particular case, the peak value is not significant but referential only as there have been no precisely measured values for a particular T402 but for a T403, and it has been modelled with a joint capacitor at the transformer connections as this is not practically implementable otherwise in ATP, and this is an approximation of reality with even capacity distribution with loading current featuring different characteristics. In Fig. 14b, Fourier analysis is shown of closing current that highlights the significant substance of the first harmonic and of one-way component. A possible $2 \mathrm{~ms}$ tolerance example in phase switching is demonstrated in Figs. 15-18. Figure 19 shows a case without considering residual capacities, making the induced voltage in the remaining phases more evident at half of its value. Surge current is minimal in controlled switching as shown in Fig. 14 and in switching on with $2 \mathrm{~ms}$ tolerance, there were peak values of $261 \mathrm{~A}$ and $177 \mathrm{~A}$ respectively; however, this is an extreme case with a similar occurrence likelihood to that of maximum switching surge in noncontrolled switching. In order to highlight the elimination of switching surges in controlled switching, no surge limiter has been included in any of the simulations.

\section{SWITCHING OFF IDLE TR 402}

In switching off idle transformer, there have been no significant surge voltages, as shown in Figs. 20 and 21. Phase-to-neutral surges did not exceed 1.25 times the nominal voltage even though $99 \%$ of the surges exceeded $1.2 U_{m}$.

\section{DETERMINING CONTROLLED SWITCHING PARAMETERS FOR SIEMENS PSD02 UNIT}

The simulation results imply that it is sufficient to control the processes of switching on the transformer as there are no significant surge voltages in switching off 

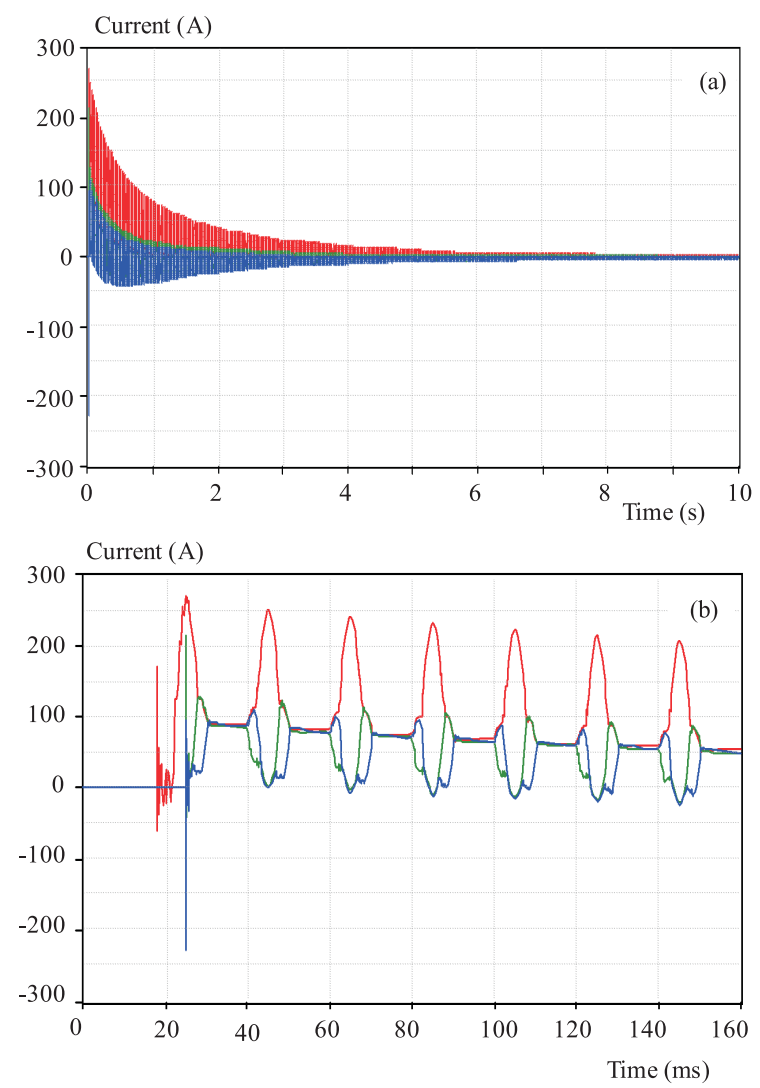

Fig. 16. Closing current curve for three phases for TR 402 Križovany in controlled switching (a) - with early phase switching by $2 \mathrm{~ms}$ against peak value, (b) - detail

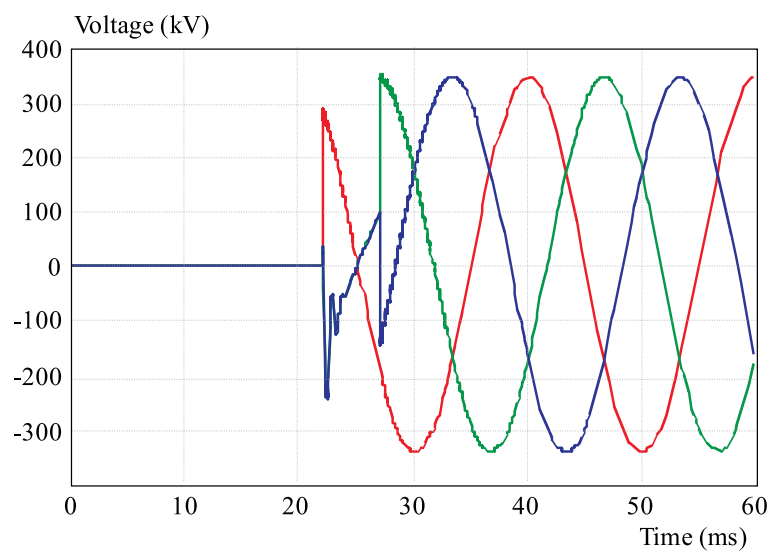

Fig. 17. Phase-to-neutral voltage curve for primary connectors of TR402 Križovany in controlled switching with delayed phase switching by $2 \mathrm{~ms}$ against peak value

in standard operation. In the following sections, ideal parameter calculation for the PSD02 unit is described.

Data provided by the manufacturer of the switch employed (best measured and for each pole):

- Mechanical operating time for the switch $-t_{\text {breaker }} \pm$ $0.1 \mathrm{~ms}$;

- In-switch arc pre-ignition time at maximum momentary phase-to-neutral voltage value $\sqrt{\frac{2}{3}} U_{n}-t_{\text {prearc }}^{1}$;
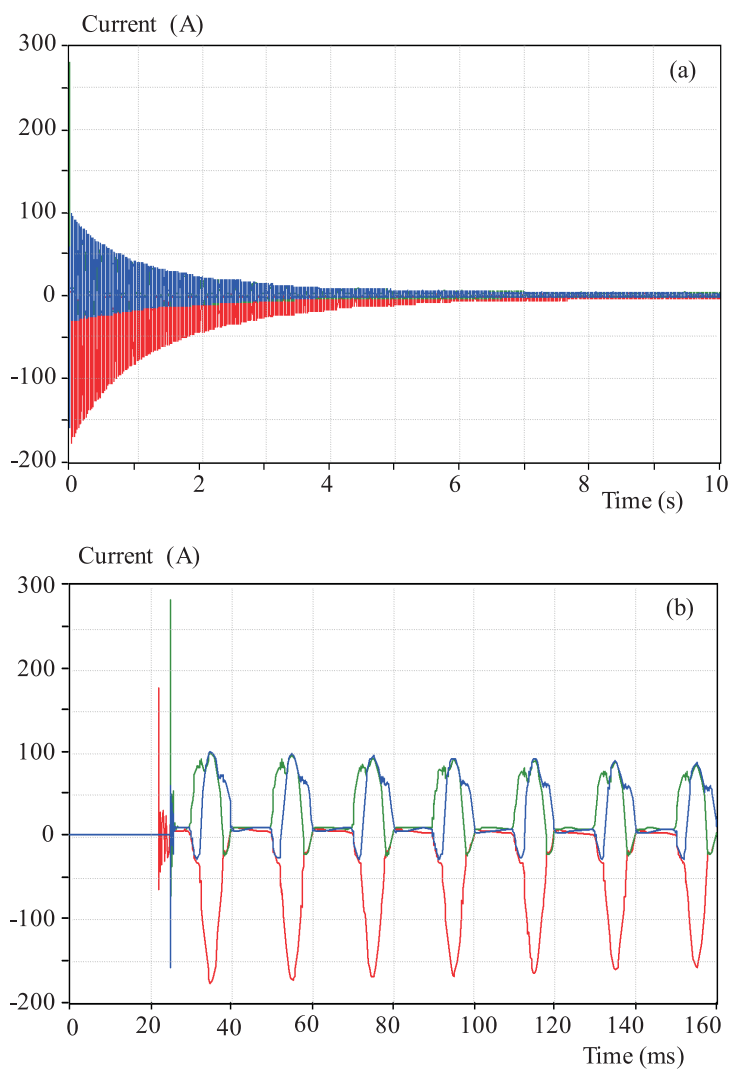

Fig. 18. Closing current curve for three phases for TR 402 Križovany in controlled switching with delayed phase switching (a) by $2 \mathrm{~ms}$ against peak value, (b) - detail

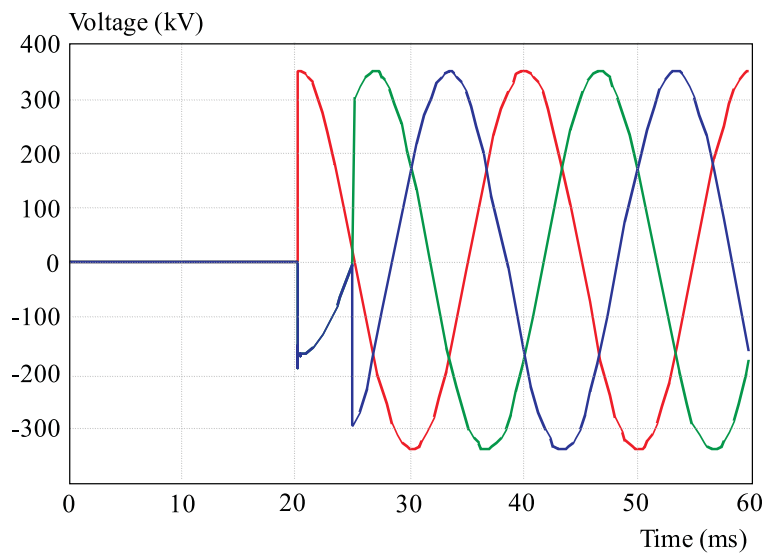

Fig. 19. Phase-to-neutral voltage curve for primary connectors of TR402 Križovany in controlled switching without considering residual capacities of windings

- In-switch arc pre-ignition time at half the maximum value of momentary phase-to-phase voltage value $\frac{\sqrt{2}}{2} U_{n} t_{\text {prearc }}^{2}$

Where $U_{n}$ is network nominal phase-to-phase voltage.

In compiling the study, it has not been possible to obtain the data from the switch manufacturer which is why the following text may serve as a theoretical guide for calculating controlled switching parameters. After obtaining the required times, the formulas may be easily populated with the values. 


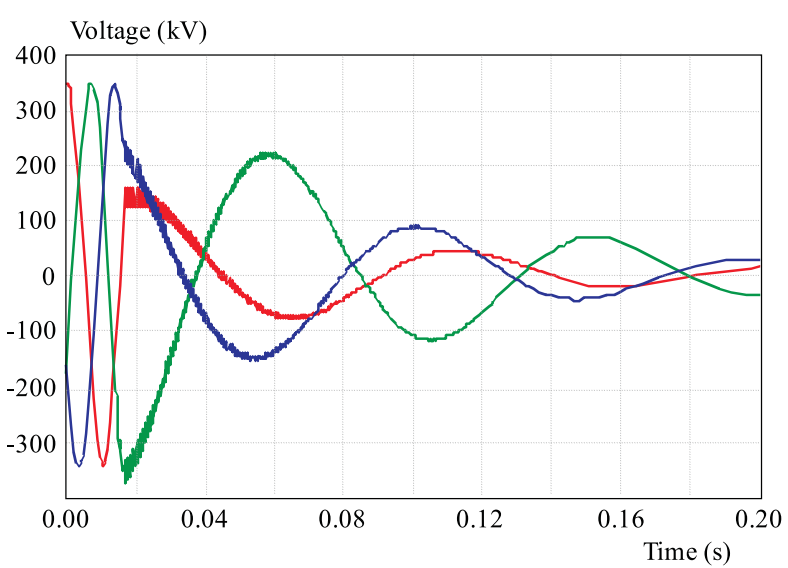

Fig. 20. Phase-to-neutral voltage curve for primary connectors of TR402 Križovany in switching off idle transformer

Set parameter (phase shift/pole) in degrees separately for each phase to

$$
A=90^{\circ}, \quad B=180^{\circ}, \quad C=180^{\circ} \text {. }
$$

Set parameter (adjusting time - closing, or arcing time - opening ) in ms separately for each phase at negative value

$$
A=-t_{\text {prearc }}^{1}, \quad B=-t_{\text {prearc }}^{2}, \quad C=-t_{\text {prearc }}^{2}
$$

Set parameter (closing time/opening time) - if not set initially - to

$$
t_{\text {breaker }} \text {. }
$$

Should it prove impossible to obtain the required switch data from the switch manufacturer, we recommend to initiate the closing test with a preignition time $t_{\text {prearc }}^{1}=3 \mathrm{~ms}$ at $\sqrt{\frac{2}{3}} U_{n}$ and $t_{\text {prearc }}^{2}=2.5 \mathrm{~ms}$ at $\frac{\sqrt{2}}{2} U_{n}$ and mechanical operating time for the switch of $t_{\text {breaker }}=$ $40 \mathrm{~ms}$.

The results of the oscillographic record of closing current at closing test (but also if initial setting is left on), we recommend to check the closing current oscillogram. Ideal closing times can be derived from calculated times: closing time, make time, command delay and closing time difference for the last closing instance recorded by the equipment, by changing values of the parameters, adjusting time - closing, or arcing time - opening - based on recorded curves towards reaching minimum closing current.

\section{CONCLUSION}

In the article, simulation results are indicated of simulating closing surge voltage for the Križovany substations in switching on newly installed idle transformers.

The simulation results imply that in non-controlled switching of idle transformers, closing surge voltage may reach theoretically 2.5 times the value of phase-to-neutral

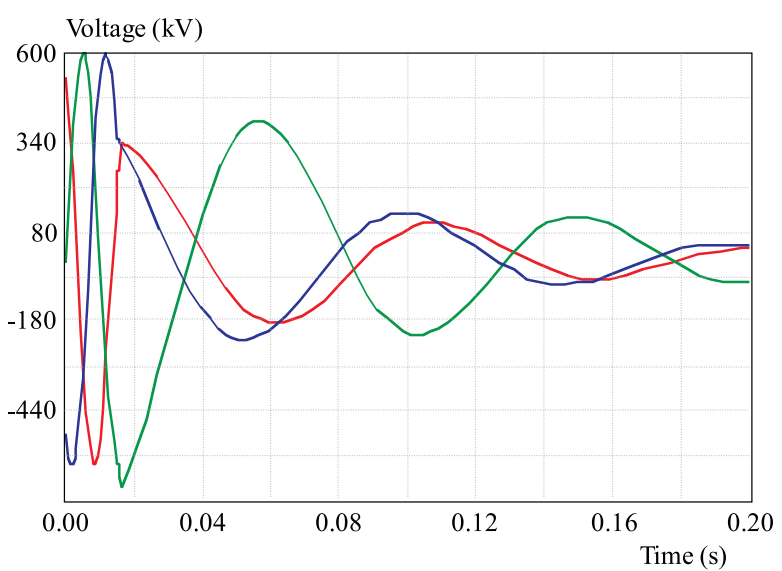

Fig. 21. Phase-to-phase voltage for primary connectors of TR402 Križovany in switching off idle transformer

voltage and 2.65 times the value of phase-to-phase voltage, with installed surge limiter a maximum of 1.75 times the nominal value of phase-to-neutral voltage and 1.54 times phase-to phase voltage and closing current may reach several times the value of idle current. The values are lower than nominal proof voltage against earth at closing impulse — $1050 \mathrm{kV}$ and $1500 \mathrm{kV}$ respectively between phases but with automated switching control, transient phenomena are eliminated, thus protecting the transformer as a preventive measure but also the transformer switch and other equipment exposed to the effects.

Based on the simulations, parameters are specified at the end automated controls on the Siemens PSD02 unit need to be set for in controlled switching of transformers with earthed neutral on the switched side. It has not been possible to obtain exact arc preignition times for specific switches and voltages and mechanical switch closing times, hence only variables are indicated for the values to which the particular parameters need to be set in follow-up to obtaining the data from the manufacturer. Should it prove impossible to obtain the data, we provide reference values that shall be used for setting up test assemblies and further elaborated in more detail in reference to obtained results as is the standard procedure in some cases for setting up controlled switching.

\section{Acknowledgements}

The paper has been compiled under grant provided by scientific research grant agency with the Ministry of Education of the Slovak Republic and the Slovak Academy of Sciences 1/3092/06 and of the Slovak Agency for Research and Development under Ref. No. APVV - 20-023505.

\section{REFERENCES}

[1] JANÍČEK, F.-MARTON, K.-BELÁŇ, A.-DOLNÍK, B.ELESCHOVÁ, Ž.-SZATHMÁRY, P.-MUCHA, M. : Determination of the overvoltage-limiter parameters in Slovak transmission system, FEI STU, Bratislava, 2006. (in Slovak)

[2] VEVERKA, A.: High Voltage Technology, Státní nakladatelství technické literatury ŠVTL, Praha-Bratislava, 1979. (in Czech) 
[3] MARTON, K. : High Voltage Technology, Vydavatestvo ALFA, Bratislava, 1983. (in Slovak)

[4] HUDEC, J.: Overvoltage and Electromagnetic Compatibility, HAKEL, Praha, 1996. (in Czech)

[5] MARTON, K.: Surge protection of electricity and computer networks, Seminar: "Počítačová bezpečnost", collection of abstracts, Banská Bystrica, pp. 23-34. (in Slovak)

[6] MARTON, K.: Placement of surge protection in computer networks, Seminar: "Počítačová bezpečnost", collection of abstracts, Agentúra SH Banská Bystrica, 1997, pp. 4-12. (in Slovak)

[7] MARTON, K.: Overvoltage protection HV VHV and UVH devices, ELMAX - collection of abstracts, Bratislava, 2002. (in Slovak)

[8] MARTON, K. et al: Theoretical analysis of overvoltage switchgear protection respecting the EMC, "20. Konferencia elektrotechnikov Slovenska", collection, Bratislava, 2004, pp. 16-28. (in Slovak)

[9] MARTON, K.: Surge phenomena in power engineering and their elimination, CD Presentation, Fakulta elektrotechnická ŽU v Žiline,, 2005. (in Slovak)

[10] MARTON, K.: Protection of computer networks against overvoltages, Vydavatestvo MERCURY Smékal, Košice, 2001. (in Slovak)

[11] Raychem Matters: ZnO limiter choice and usage atHV lines Energy Division Raychen 1996.

[12] STN EN 99-5 Surge voltage protector, recommendations for the selection and use.

[13] BIEKFORD, J. P. et al : Computation of Power System Transients, Peter Peregrinus Ltd., England, 1976.

[14] ABB Wettingen, User guide, overvoltage protection.

[15] TICHÝ, V.: ZnO overvoltage limiters, CD nosič, TYCO, RAYCHEN, Energy Division, Bratislava, 2004. (in Slovak)

[16] HASMAN, T.: Surge in power engineering networks, Vydavatelství ČVUT, Praha, 1997. (in Czech)

[17] ŠANDRIK, P.: High voltage technology, STU v Bratislave, 2004. (in Slovak)

[18] MAYER, D.: Electrodynamics in power engineering, BEN Technická literatura, Praha, 2005. (in Czech)

[19] KUTÁČ, J. : SPBI Praha, Dehn u. Söhne Neumarkt 2006, New proposals for EU standards in theory and practice, EN IEC 62305 Lightning protection. (in Czech)

[20] GERT, R.: Operating surges in power systems, SNTL, Praha, 1964 pages142. (in Czech)

[21] JIRKŮ, J.-POPOLANSKÝ, F.: Overvoltage on in-air power network, SNTL, Praha, 1966, pp. 256. (in Czech)

[22] DUGAN, R. C.-McCRANAGHAN, M. F.-BEATY, H. W. : Electrcal Power Systems Quality, McGraw-Hill, New York, 1996, pp. 265.

[23] GREENWOOD, A.: Electrical Transients in Power Systems, John Wiley \& Sons, New York, 1991 pages751.

[24] STN EN 6099-4 surge voltage protection - non arrester gap surge voltage protection.

[25] STN EN 60071-1 Insulation coordination - definitions, principles, rules.

[26] STN EN 60071-2 Insulation coordination - users guide.

[27] ABB Surge Arresters - Buyer's Guide Edition 5, 2004-10. Catalog Publ: 1HSM 9543 12-00en.

[28] TRIDELTA Metal Oxide Surge Arrester for High Voltage Systems.

Received 8 September 2009

František Janíček graduated from the Faculty of Electrical Engineering (EF) at the Slovak University of Technology in 1979 and took the position of assistant lecturer with the Department of Electrical Power Engineering of EF SVT. In 1984 received his $\mathrm{PhD}$ in the field of Electrical Power Engineering, in 1989, was appointed Associate Professor from 1999 he is a Full Professor. He was the Dean of the Faculty of Electrical Engineering and Informatics of STU in Bratislava (2000 - 2007), and the Vice rector for development of the Slovak University of Technology since (2007). He is a leading expert in the area of electrical power engineering. He authored or coauthored university textbooks and lecture books, four expert monographs, more than 50 articles in periodicals, and more than 100 lectures at international scientific conferences (including invited lectures). He has solved more than 80 projects for technical practice. One of the co-founders of the Internet based information and education project INFELEN (information on electrical power engineering), founder of EE Magazine and a member of the editorial board with the same. He is a member of the Slovak board of WEC SR, statutory officer of the EE Association (8 participating organisations) and a member of several scientific boards of SR universities. He was a reviewer of several major projects relating to the liberalization of electricity markets and a member of the team that developed the SR Energy Policy. As of 2006, he has been the chairman of the board for technical sciences with the Slovak Research and Development Agency.

Martin Mucha graduated from the Faculty of Electrical Engineering and information technology at the Slovak University of Technology in 2004, in the same year he took the position of assistant lecturer with the Department of Electrical Power Engineering of FEI STU. In 2007, he received his $\mathrm{PhD}$ in the field of Electrical Power Engineering at EI STU. At present is working on power system protection research.

Karol Česnek graduated from the Faculty of SED VD in 1970. He started with the Department of Maintenance of Power Transformers in ZSE Bratislava. In 1981 he became Head of Department for maintenance and prophylactic measurements in electric distribution with a nationwide scope. Since 1984 he worked as Deputy Director of Operations and Technology ZSE Bratislava. Since 1990, he worked as Deputy Director General SEP Bratislava, where later in the transformation to the SE and Bratislava tenure as the director and Chairman of the directorate. worked as project manager of reconstruction Tr Kriovany. He cooperated and led the working group to develop operating rules for distribution and power transformers. The international symposia and conferences within the group Interelektro had 10 technical contributions.

Jozef Kováčik graduated from the Faculty of Electrical Engineering (EF) at the Slovak University of Technology (SVT, later STU) in 1981 and started with the Department of Maintenance of Power Transformers in ZSE Bratislava. In that position he was involved on Operational Diagnostics of power devices within power substations. Regarding of technical focus of that Department one was dealing within whole territory of Slovakia. It was done in connection with SE Bratislava and SEPS Bratislava. Nowadays these technical activities are doing in connection with company VUJE, a.s. Trnava. He authored or co-authored 15 articles in periodicals, and 10 lectures at international scientific conferences. In area of Diagnostics of Power Transformers the technical works were done within Power Grid of Slovakia as well with partners from abroad in Europe. 